\title{
PERSPECTIVE
}

\section{Continuity in Undergraduate Medical Education: Mission Not Accomplished}

\author{
Daniel B. Evans, MD' , Bruce L. Henschen, MD, MPH', Ann N. Poncelet, MD', \\ LuAnn Wilkerson, $E \mathrm{CD}^{3}$, and Barbara Ogur, $M D^{4}$
}

\begin{abstract}
'Department of Medicine, Division of General Internal Medicine and Geriatrics, Northwestern University Feinberg School of Medicine, Chicago, IL, USA; ${ }^{2}$ Department of Neurology, University of California, San Francisco, CA, USA; ${ }^{3}$ Department of Medical Education, Dell Medical School, The University of Texas at Austin, Austin, TX, USA; ${ }^{4}$ Cambridge Health Alliance and Center for Primary Care, Harvard Medical School, Boston, MA, USA.
\end{abstract}

Evidence is mounting that longitudinal medical student clerkships provide better educational experiences than traditional block clerkship “silos.” Education studies across institutions demonstrate positive effects of continuity on medical students, including creating patientcentered learning environments, improving fidelity of evaluations and feedback, improving medical student patient-centeredness, enabling more autonomous functioning in the clinical workplace, and increased recruitment and retention of students into primary care careers. Outcome studies show potential for longitudinal students to add value to patient care. This perspective piece summarizes the current evidence basis for longitudinal clerkships broken down by Kirkpatrick level (reactions, perceptions/attitudes, knowledge, behaviors, and patient benefits). Despite this evidence, expansion of longitudinal clerkships has been slow-i.e., fewer than half of current US medical schools offer one. While more recent curricular innovations center around Entrustable Professional Activities (EPAs), there are clear opportunities for medical schools to use longitudinal clerkships as a lens through which EPAs can be effectively evaluated. This perspective highlights the synergy between longitudinal clerkships and EPAs, showing that successful implementation of the former should empower the latter. While large, complex educational interventions are daunting tasks, change is needed. Regulatory organizations should mandate continuity-focused experiences for US medical graduates.

KEY WORDS: continuity in medical education; undergraduate medical education; value-added medical education; Longitudinal Integrated Clerkship; Entrustable Professional Activities.

J Gen Intern Med 34(10):2254-59

DOI: $10.1007 / \mathrm{s} 11606-019-04949-0$

(C) Society of General Internal Medicine 2019

\begin{abstract}
A $\mathrm{s}$ academic medical centers evolve in response to a confluence of scientific, economic, and regulatory pressures, leaders in medical education are trying to redefine the role of undergraduate training. ${ }^{1,2}$ Inpatient medical and surgical services - traditional anchors of discipline-based clerkships - have gradually become high-throughput systems
\end{abstract}

Published online July 25, 2019 where chronic illness and discontinuity are the norms. "Routine" care has increasingly migrated from academic medical centers towards immediate care centers, retail pharmacy clinics, and outpatient surgicenters, reinforcing a general perception of the "disappearing doctor." In this rapidly changing landscape, our impressionable trainees often feel disconnected. They see the sickest of the sick in the hospital but miss out on the rewarding therapeutic relationships, developed over time in ambulatory settings. They miss out on the thoughtful, professionally satisfying, and proactive care-what Dr. Atul Gawande eloquently describes as "the heroism of incremental care" - that is provided in high functioning primary care clinics. ${ }^{4}$ It is time for change.

\section{ARGUMENTS FOR ENHANCED CONTINUITY IN MEDICAL EDUCATION}

Longitudinal care experiences, promoted by medical education leaders for decades, enable students to experience continuity with patients, preceptors, and peers. ${ }^{5-8}$ The authors of the Carnegie Report in 2010 agreed that longitudinal connections with patients drive clinical and basic science knowledge integration, provide case-based opportunities for meaningful reflection, engage learners in challenging clinical problems in real time, and enable them to participate authentically in inquiry-driven improvement projects. ${ }^{9}$ More than opportunities for learning, however, continuity experiences teach students how to be humanistic, professional physicians. Ian McWhinney, known as "Canada's Founding Father of Family Medicine," wrote, "values and attitudes are not transmitted by lectures or books, they have to pervade the whole environment in which learning takes place. The essence of general practice is an unconditional and open-ended commitment to one's patients. The kind of commitment [where] the physician will stay with a person whatever the problem may be, and will do so because commitment is to people more than to a body of knowledge." ${ }^{10}$ Longitudinal clerkships enable these values - empathy, commitment to patients, health equity, and humanism - to pervade the learning environment as students witness their preceptors, and 
themselves, building and maintaining relationships with patients. If we still believe in this longitudinal doctorpatient commitment, then continuity opportunities for our students must be a key aspect of educational design, rather than an optional track for a select few. Just as our patients need a consistent "medical home" where they receive coordinated care, our students need a consistent "educational home" where they can participate in the delivery of high-quality patient care over time. ${ }^{11}$

\section{EVIDENCE FOR LONGITUDINAL CLERKSHIPS}

We organize the evidence of longitudinal clerkships by Kirkpatrick's Levels of Evidence - a hierarchy often used for evaluating the results of educational programs. ${ }^{12}$

\section{Level 1: Learner and Preceptor Reactions}

Longitudinal clerkship structures create safe learning environments where students can meaningfully engage with patients over time, gradually take responsibility with appropriate supervision, and foster an emerging physician identity "grounded in an ethic of caring." clerkships receive higher student ratings for faculty teaching, positive role modeling, feedback, and overall educational experience. ${ }^{14-16}$ Students see the feedback given to them by longitudinal preceptors as being focused more on their own development, emphasizing a partnership with their evaluators that gives them the confidence to grow in a supportive learning environment. ${ }^{17}$ Students in longitudinal clerkships are afforded more authentic responsibilities in the care of patients, and they feel their preceptors have a more accurate assessment of their abilities. Qualitative studies find that students perceive improvements in career mentorship, personal support, learning opportunities about chronic illness, and development of communication skills. ${ }^{18,19}$

Preceptor reactions are also positive. Rural family medicine preceptors comment on the development of trusting relationships with their trainees over time, improved teaching opportunities anchored in personal relationships, and more collaborative learning goals focused on their learner's unique career goals. ${ }^{20}$ Preceptors in an urban longitudinal clerkship feel a strong responsibility for their student's learning and appreciate a deep sense of reward observing their students' growth. ${ }^{21} \mathrm{~A}$ cohort of urban primary care preceptors in the Education-Centered Medical Home (ECMH) longitudinal clerkship voted with their feet to return and precept in 110 out of 118 retention opportunities. $^{22}$ Others describe how the benefits of longitudinal clerkships align with the goals of community health systems including positive effects on faculty engagement, professional satisfaction, and potential impact on academic appointment and long-term faculty recruitment. ${ }^{23}$

\section{Level 2a: Modification of Perceptions and Attitudes}

Students in longitudinal clerkships perceive an expanded scope and depth to their individual roles in patient care environments. ${ }^{24}$ Students in traditional preceptorship-style curricula describe themselves as "learners," "visitors," or "diagnosticians" practicing their clinical skills. In contrast, students in longitudinal models see themselves as "caregivers," "advocates," and "mentors". ${ }^{25}{ }^{26}$ Longitudinal students have greater recognition of and respect for their interdisciplinary team members and perceive that their primary care clinic experiences are more patient-centered. ${ }^{27}$ Longitudinal students report continuity with preceptors and peers gives them a sense of stability and creates a "safe harbor" which fosters student resilience. ${ }^{28}$ Students perceive less exposure to the negative aspects of the "hidden curriculum" and have significant improvements in patient-centered attitudes. ${ }^{14-16}$ These improvements increase with greater duration of the clerkship, suggesting a dose-response relationship. In other studies, students perceive higher confidence in dealing with uncertainty, being self-directed, understanding the health care system, ${ }^{14}$ quality improvement objectives, ${ }^{16}$ and dealing with ethical dilemmas. ${ }^{29}$ In multiple qualitative studies, longitudinal clerkship students comment on the importance of longitudinal primary care relationships and growing into the role of a professional doctor - themes that are notably absent in interviews with students in traditional clerkship models. ${ }^{25}$

\section{Level 2b: Acquisition of Knowledge and Skills}

Removing students from traditional discipline-based block clerkships raises fears of less exposure to some tertiary medical conditions and introduces the potential for unintended new knowledge gaps. Evidence to date suggests that these fears are unfounded. In studies across multiple institutions and involving multiple formats, the performances on knowledge-based US Medical Licensing Exams are comparable across longitudinal, hybrid, and block clerkship models. ${ }^{14-16,30}$ In several instances, longitudinal students outperform their block rotation peers on clinical skill assessments and National Board of Medical Examiners subject-based knowledge exams. ${ }^{14-16,30}$

\section{Level 3: Change in Behavior}

Creating a longitudinal education program is time-intensive and costly. But what if continuity in undergraduate medical education has durable effects on future physician behavior? Evidence shows that longitudinal clerkship students spend more time at the bedside, engage in patient care more independently, and have more opportunities for patient continuity. ${ }^{17}$ They are more likely to achieve meaningful relationships with patients and to report making a real difference in the health or well-being of their patients. ${ }^{14,16}$ Residency programs directors rate the clinical performance of graduates of rural longitudinal programs higher than graduates from traditional 
block clerkships. ${ }^{31,32}$ Even more encouraging, the improved patient-centeredness seen among students persists when reassessed after graduation, implying a lasting effect from their undergraduate training. ${ }^{33}$ Structured interviews among graduates who later became physician leaders cite participation in the 4-year longitudinal docent system during their undergraduate training as a critical factor in their future successes as leaders in medicine. ${ }^{34}$

\section{Level 4: Change in Practice and Benefits to Patients}

Several rural-based longitudinal programs have aided recruitment of students into primary care fields and enhanced retention of faculty, thus proving their utility as a primary care workforce pipeline. ${ }^{27,}{ }^{31}$ Regarding patient outcomes, little evidence is available, but this may be changing. Patients seeing students in different longitudinal clerkship models value their relationships with their students and perceive them as playing a "physician-like" role. ${ }^{35}$ In addition, they report being more empowered in their own care as a result of working with a longitudinal student. ${ }^{36}$ O'Neill et al. showed the feasibility of tracking quality metrics as part of a longitudinal clerkship with promising trends towards improved preventative care. ${ }^{37}$ Patient outcomes data from one longitudinal clerkship demonstrated improved influenza vaccination rates and increased rates of screening for HIV, cervical cancer, and hepatitis C. ${ }^{16,}{ }^{38}$ If structured and supervised properly, students may be able to serve as health coaches and quality managers for complex patients. ${ }^{39}$ Further studies are clearly needed to replicate these early findings - but these future studies can only be done if longitudinal programs are sustained and expanded to additional institutions.

\section{MERGING THE NEEDS OF OUR STUDENTS WITH THE NEEDS OF ACADEMIC MEDICAL CENTERS}

Larger trends in US health care, such as the aging of our population, the rise of chronic illness care, and the fragmentation of our networks, may be viewed as threats to medical education. Alternatively, these challenges could be viewed as opportunities to get students more engaged in the health care system earlier, more meaningfully, and with the stated purpose to "add value. ${ }^{, 40-42}$ Rather than a block system devoid of continuity, fraught with harmful handoffs, ${ }^{43}$ and absent durable therapeutic relationships, a future undergraduate system built with continuity as the organizing principle could allow the needs of our students, the needs of our community health systems, ${ }^{23}$ and the needs of our patients to co-evolve towards better care.

\section{CURRENT STATE OF LONGITUDINAL CLERKSHIPS}

In spite of the aforementioned advantages, expansion of longitudinal clerkship models has been modest. ${ }^{44}$ Fewer than half of US medical schools offer a longitudinal program; ${ }^{45}$ most are optional tracks for self-motivated students rather than core clerkships. Initial excitement among medical educators manifest by rising publications from 2007 to 2014 has now declined (Fig. 1). The data depicted in the figure shows that medical educators are focusing innovation and publication efforts on Entrustable Professional Activities (EPAs) rather than Longitudinal Integrated Clerkships (LICs). If EPAs are to become valid checkpoints for student promotion, then we need longitudinal programs to give learners sufficient time with their teams in order to build trust. ${ }^{46,}{ }^{47}$ Olle Ten Cate and Robert Englander write, "Only when there is sufficient time to build grounded trust can the amount of supervision be tailored to the situation and decreased over time. Longitudinal clerkships offer just the type of relationship building over time that supports grounded trust and therefore entrustment decisions. ${ }^{47}$ For some EPAs, longitudinal assessment is critical. Direct observation of history taking and physical exam skills (EPA\#1); recommending screening tests at the right time, for the right patient (EPA\#3); and contributing to the culture of safety and improvement (EPA\#13) require making entrustment decisions about student behavior over time - not simply during a single encounter. ${ }^{48}$ Conversely, longitudinal programs cannot succeed without rigorous competencybased evaluation systems focused on progressive entrustment. The reality is we need both... this should not be an either/or proposition.

It takes an average of 17 years between the initial publication of a medical innovation and subsequent wide-scale adoption as standard practice. ${ }^{49}$ If continuity-focused education reforms follow a similar path, then we have just 4 years remaining to go from the current status of $\sim 25 \%$ penetrance among current US medical students and ramp up to capture $100 \%$ of our graduates. This will not be easy.

Educational innovations are complex service interventions that operate in complex social systems. ${ }^{50}$ Barriers to longitudinal clerkships are real and include (but are not limited to) balancing competing curricular and research demands, physical clinic space requirements, the need for community clinic partnerships, recruitment and retention of core primary care teaching faculty, and the necessary cost of reimbursing faculty who are willing to commit to teach and mentor student teams across much longer arcs of training than the traditional 4-week block. Incremental change towards a future of "longitudinal clerkships for all" is possible - but stagnation towards a twotiered system of "longitudinal have's and have not's" as a result of limited funding or competing curricular pressures seems equally likely based on recent trends. Disseminating evidence alone will not change the currently entrenched block rotation culture; incentives (carrots) or force-functions (sticks) are needed (Table 1). ${ }^{51,52}$ We believe it is time for regulatory bodies to mandate a longitudinal, continuity-focused experience for every US medical graduate. Several different longitudinal structures have proven track records of success, including replacing the third-year core clerkships with 


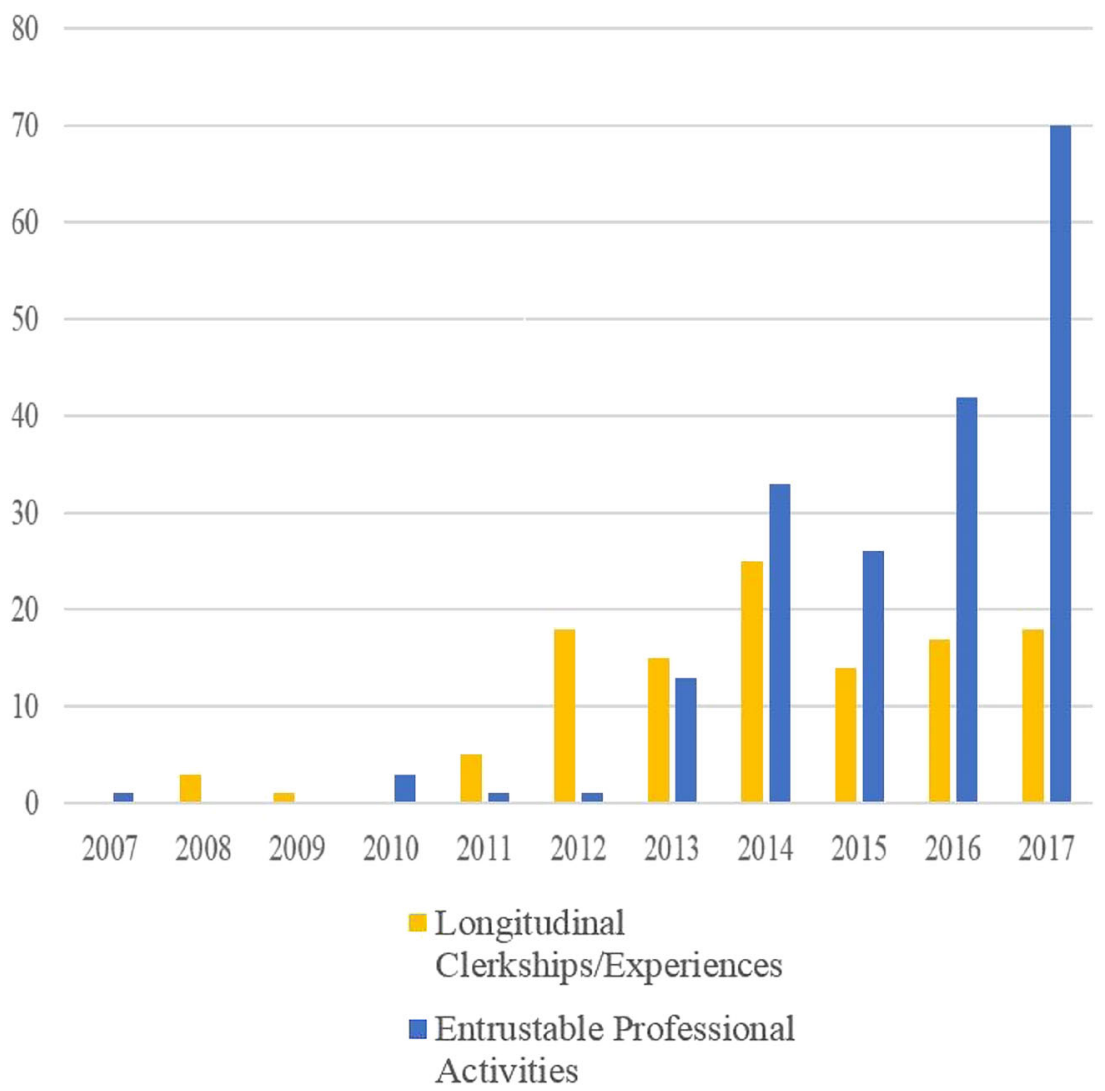

Figure 1 Articles in PubMed from 2007 to 2017 focused on medical student longitudinal clerkships or longitudinal experiences compared with articles focused on Entrustable Professional Activities for medical students.

longitudinal integrated clerkships, ${ }^{21,} 29$ or integrating a 4-year longitudinal ambulatory experience into the curriculum. ${ }^{22,31}$ Academic medical centers, whether urban or rural, state or

Table 1 Current Medical School Accreditation Standards and Regulatory Metrics Focused on Continuity, Longitudinal Care, or Development of Therapeutic Patient Relationships

\begin{tabular}{|c|c|}
\hline $\begin{array}{l}\text { Number of patient return visits required by } \\
\text { LCME in order for a US medical student to } \\
\text { graduate }\end{array}$ & 0 \\
\hline $\begin{array}{l}\text { Number of authentic, longitudinal, } \\
\text { therapeutic patient relationships required by } \\
\text { LCME in order for a US medical student to } \\
\text { graduate }\end{array}$ & 0 \\
\hline $\begin{array}{l}\text { Number of patient satisfaction or feedback } \\
\text { surveys required by LCME in order for a US } \\
\text { medical student to graduate }\end{array}$ & 0 \\
\hline $\begin{array}{l}\text { Number of patient outcome audits or quality } \\
\text { metric report cards required by LCME in } \\
\text { order for a US medical student to graduate }\end{array}$ & 0 \\
\hline Number of questions on the AAMC & 0 \\
\hline $\begin{array}{l}\text { Graduate Questionnaire relating to } \\
\text { continuity, longitudinal care, or therapeutic } \\
\text { relationships with patients }\end{array}$ & \\
\hline $\begin{array}{l}\text { Number of Core AAMC Entrustable } \\
\text { Professional Activities (EPAs) which are } \\
\text { focused on continuity, longitudinal care, or } \\
\text { therapeutic relationships with patients }\end{array}$ & 0 out of 13 \\
\hline $\begin{array}{l}\text { Number of LCME standards which have any } \\
\text { mention of continuity, longitudinal care, or } \\
\text { therapeutic relationships with patients }\end{array}$ & $\begin{array}{l}1 \text { out of } 93 \\
\text { (standard \# 7.2) }\end{array}$ \\
\hline $\begin{array}{l}\text { Specific content of LCME standards } \\
\text { regarding continuity, longitudinal care, } \\
\text { or therapeutic relationships with patients }\end{array}$ & $\begin{array}{l}3 \text { words out of a } 35- \\
\text { page document }\end{array}$ \\
\hline
\end{tabular}

private, research or primary care focused, have flexibility to build programs from these templates that fit their diverse needs. We must recognize that continuity of care, continuity of supervision, continuity of system, and continuity with peers are critical aspects of modern medical practice and prerequisites for high-quality undergraduate medical education. We must repair the disconnects which our fragmented block rotations have unwittingly created and perpetuated. ${ }^{53}$

We are currently practicing medicine in the midst of a chronic care crisis. ${ }^{54}$ Chronic care must be delivered incrementally. Chronic illness does not abide by the constraints of a 4-week clerkship calendar. Understanding how to prevent or mitigate chronic illness is the challenge of primary care in the twenty-first century. Learning to master chronic care requires managing some patients chronically! Graduating a fourth-year student who has never seen an asthmatic, diabetic, hypertensive, or obese patient back for a follow-up visit and who has never forged a therapeutic relationship with a patient longer than a 7-day hospital stay is simply unacceptable. Similarly, asking educators to make entrustment decisions about core primary care skills such as patient counseling and preventative screening is unrealistic if they only work with a student for a week. It is time to make continuity the norm, not the exception. How long must our students wait before these improved training models become standard practice? The 17-year mark is coming soon... we are far from accomplishing our mission. 
Corresponding Author: Daniel B. Evans, MD; Department of Medicine, Division of General Internal Medicine and GeriatricsNorthwestern University Feinberg School of Medicine, Chicago, IL, USA (e-mail: daevans@nm.org).

\section{Compliance with Ethical Standards:}

Conflict of Interest: The authors declare that they do not have a conflict of interest.

\section{REFERENCES}

1. Commonwealth Fund. Envisioning the Future of Academic Health Centers. 2003. Available at: http://www.commonwealthfund.org/publications/fund-reports/2003/feb/envisioning-the-future-of-academichealth-centers. Accessed October 23, 2018.

2. Whitcomb ME. Redesigning clinical education: a major challenge for academic health centers. Acad Med 2005;80(7):615-616.

3. Abelson J. The Disappearing Doctor: How Mega-mergers are changing the business of medical care. Available at: https://www.nytimes.com/ 2018/04/07/health/health-care-mergers-doctors.html. Accessed October 23, 2018.

4. Gawande A. The Heroism of Incremental Care. 2017. Available at: https:/ /www.newyorker.com/magazine/2017/01/23/the-heroism-ofincremental-care . Accessed October 23, 2018.

5. Hirsh DA, Ogur B, Thibault GE, Cox M. "Continuity" as an organizing principle for clinical education reform. N Engl J Med 2007;356(8):858866.

6. Bell SK, Krupat E, Fazio SB, Roberts DH, Schwartzstein RM. Longitudinal pedagogy: a successful response to the fragmentation of the third-year medical student clerkship experience. Acad Med 2008;83(5):467-475.

7. Hudson JN, Poncelet AN, Weston KM, Bushnell JA, A Farmer E. Longitudinal integrated clerkships. Med Teach 2017;39(1):7-13.

8. Irby DM. Teaching and learning in ambulatory care settings: a thematic review of the literature. Acad Med 1995;70(10):898-931.

9. Cooke M, Irby DM, O'Brien BC, Carnegie Foundation for the Advancement of Teaching. Educating physicians: A call for reform of medical school and residency. 1st ed. San Francisco: Jossey-Bass; 2010.

10. Weston ww, whitehead $\mathbf{C}$. Why continuity matters: Ian McWhinney's insights for 21st-century medical education. Can Fam Physician 2014;60(1):11-13

11. Evans DB. The patient-centered medical home as a curricular model: medical students need an "educational home". Acad Med 2011;86(11):e2.

12. Yardley S, Dornan T. Kirkpatrick's levels and education 'evidence'. Med Educ 2012;46(1):97-106.

13. Konkin J, Suddards C. Creating stories to live by: caring and professional identity formation in a longitudinal integrated clerkship. Adv Health Sci Educ Theory Pract 2012;17(4):585-96.

14. Hirsh D, Gaufberg E, Ogur B, et al. Educational outcomes of the Harvard Medical School-Cambridge integrated clerkship: a way forward for medical education. Acad Med 2012;87(5):643-650.

15. Teherani A, Irby DM, Loeser H. Outcomes of different clerkship models: longitudinal integrated, hybrid, and block. Acad Med 2013;88(1):35-43.

16. Henschen BL, Bierman JA, Wayne DB, et al. Four-year educational and patient care outcomes of a team-based primary care longitudinal clerkship. Acad Med 2015;90(11 Suppl):S43-49.

17. O'Brien BC, Poncelet AN, Hansen L, et al. Students' workplace learning in two clerkship models: a multi-site observational study. Med Educ 2012: 46:(6) 613-624.

18. Wamsley MA, Dubowitz N, Kohli P, Cooke M, O'Brien BC. Continuity in a longitudinal out-patient attachment for Year 3 medical students. Med Educ 2009;43(9):895-906.

19. Hauer KE, O'Brien BC, Hansen LA, et al. More is better: Students describe successful and unsuccessful experiences with teachers differently in brief and longitudinal relationships. Acad Med 2012;87(10)138996.

20. Cuncic C, Regehr G, Frost H, Bates J. It's all about relationships: A qualitative study of family physicians' teaching experiences in rural longitudinal clerkships. Perspect Med Educ 2018;7(2):100-109.

21. Teherani A, O'Brien BC, Masters DE, Poncelet AN, Robertson PA, Hauer KE. Burden, responsibility, and reward: preceptor experiences with the continuity of teaching in a longitudinal integrated clerkship. Acad Med 2009;84(10 Suppl):S50-3.

22. Henschen BL, Garcia P, Jacobson B, et al. The patient centered medical home as curricular model: perceived impact of the "education-centered medical home". JGIM. 2013;28(8):1105-1109.

23. Poncelet AN, Mazotti LA, Blumberg B, Wamsley MA, Grennan T, Shore WB. Creating a longitudinal integrated clerkship with mutual benefits for an academic medical center and a community health system. Perm J 2014; 18(2):50-56.

24. O'Brien BC, Hirsh D, Krupat E, et al. Learners, performers, caregivers, and team players: Descriptions of the ideal medical student in longitudinal integrated and block clerkships. Med Teach 2016;38(3):297-305.

25. Golden BP, Henschen BL, Gard LA et al. Learning to be a doctor: Medical students' perception of their roles in longitudinal outpatient clerkships. Patient Educ Couns. 2018 Nov; 101(11):2018-2024.

26. Hauer KE, Hirsh D, Ma I, et al. The role of role: learning in longitudinal integrated and traditional block clerkships. Med Educ 2012;46(7):698-710.

27. Walters L, Greenhill J, Richards J, Ward H, Campbell N, Schuwirth LW. Outcomes of longitudinal integrated clinical placements for students, clinicians and society. Med Educ 2012;46(11): 1028-1041.

28. Greenhill J, Fielke KR, Richards JN, Walker LJ, Walters LK. Towards an understanding of medical student resilience in longitudinal integrated clerkships. BMC Med Educ 2015;15:137.

29. Ogur B, Hirsh D, Krupat E, Bor D. The Harvard Medical SchoolCambridge integrated clerkship: An innovative model of clinical education. Acad Med 2007;82(4):397-404.

30. McLaughlin K, Bates J, Konkin J, Woloschuk W, Suddards CA, Regehr G. A comparison of performance evaluations of students on longitudinal integrated clerkships and rotation-based clerkships. Acad Med 2011;86(10 Suppl):S25-29.

31. Drees BM, Arnold L, Jonas HS. The University of Missouri-Kansas City School of Medicine: Thirty-five years of experience with a nontraditional approach to medical education. Acad Med 2007;82(4):361-369.

32. Woloschuk W, Myhre D, Jackson W, McLaughlin K, Wright B. Comparing the performance in family medicine residencies of graduates from longitudinal integrated clerkships and rotation-based clerkships. Acad Med 2014;89(2):296-300.

33. Gaufberg $\mathbf{E}$, Hirsh $\mathbf{D}$, Krupat $\mathbf{E}$, et al. Into the future: patientcenteredness endures in longitudinal integrated clerkship graduates. Med Educ 2014;48(6):572-582.

34. Arnold L, Cuddy PG, Hathaway SB, Guaintance JL, Kanter SL. Medical school factors that prepare students to become leaders in medicine. Acad Med 2018;93(2):274-282.

35. Poncelet AN, Wamsley M, Hauer KE, Lai C, Becker T, O'Brien BC. Patient views of continuity relationships with medical students. Med Teach 2013;35(6):465-71.

36. Hudson JN, Knight PJ, Weston KN. Patient perceptions of innovative longitudinal integrated clerkships based in regional, rural and remote primary care: a qualitative study. BMC Fam Pract 2012;13:72

37. O'Neill SM, Henschen BL, Unger ED, et al. Educating future physicians to track health care quality: Feasibility and perceived impact of a health care quality report card for medical students. Acad Med 2013:88(10):1564-1569.

38. Russi AE, Bhaumik S, Herzog JJ, Tschoe M, Baumgartner AC. Impact of an education-centered medical home on quality at a student-volunteer free clinic. Med Educ Online 2018;23:1. https://doi.org/10.1080/ 10872981.2018.1505401.

39. Gonzalo JD, Dekhtyar M, Hawkins RE, Wolpaw DR. How can medical students add value? Identifying roles, barriers, and strategies to advance the value of undergraduate medical education to patient care and the health system. Acad Med 2017;92(9):1294-1301.

40. Curry RH. Meaningful roles for medical students in the provision of longitudinal patient care. Jama. 2014;312(22):2335-2336.

41. Lin SY, Schillinger E, Irby DM. Value-Added Medical Education: Engaging Future Doctors to Transform Health Care Delivery Today. J Gen Intern Med. 2014.

42. Curry RH. Medical students as health coaches, and more: Adding value to both education and patient care. Isr J Health Policy Res 2017;6(1):65.

43. Englander R, Carraccio C. A Lack of Continuity in Education, Training, and Practice Violates the "Do No Harm" Principle. Acad Med 2018;93(3S):S12-S16.

44. Gheihman G, Jun T, Young GJ, et al. A review of longitudinal clinical programs in US medical schools. Med Educ Online 2018;23(1):1444900.

45. Association of American Medical Colleges. Number of Medical Schools Offering Longitudinal Integrated Clerkships. Available at: https://www. aamc.org/initiatives/cir/402412/01a.html. Accessed October 23, 2018. 
46. Hirsh DA, Holmboe ES, ten Cate O. Time to trust: Longitudinal integrated clerkships and entrustable professional activities. Acad Med 2014;89(2):201-204.

47. Ten Cate O, Englander R. LICs and entrustable professional activities: A perfect match. In Longitudinal Integrated Clerkships: Principles, Outcomes, Practical Tools and Future Directions. Poncelet AN and Hirsh D (Ed): North Syracuse, Gegensatz Press. 2016, Pages 261-269.

48. Association of American Medical Colleges. Core Entrustable Professional Activities for entering residency. Available at: https://www.aamc.org/ download/482214/data/epa13toolkit.pdf. Accessed October 23, 2018.

49. Morris ZS, Wooding $\mathbf{~ S , ~ G r a n t ~} \mathbf{J}$. The answer is 17 years, what is the question: Understanding time lags in translational research. J R Soc Med 2011;104(12):510-520.

50. McGaghie WC. Implementation science: Addressing complexity in medical education. Med Teach 2011;33(2):97-98.
51. Association of American Medical Colleges. Medical School Graduation Questionnaire. 2017 All Schools Summary Report. Available at: https:// www.aamc.org/download/481784/data/2017gqallschoolssummaryreport.pdf . Accessed October 23, 2018.

52. Liaison Committee on Medical Education. Standards for Accreditation of Medical Education Programs Leading to the MD Degree. 2018. Available at: http://lcme.org/publications/. Accessed October 23, 2018.

53. Stevens $\mathbf{C D}$, Wilkerson $\mathbf{L}$, Ujitdehaage $\mathbf{S}$. Longitudinal continuity experiences can repair disconnects in the core clerkships for medical students. Acad Med 2014 Feb;89(2): 205-207.

54. Bodenheimer T, Wagner EH, Grumbach K. Improving Primary Care for Patients With Chronic Illness. JAMA. 2002;288(14):1775-1779.

Publisher's Note Springer Nature remains neutral with regard to jurisdictional claims in published maps and institutional affiliations. 